ВЕРИГА Валерий Львович - соискатель кафедры мировых политических процессов Московского государственного института международных отношений (университет) МИД РФ (119454, Россия, г. Москва, nр-кт Вернадского, 76, vlveriga@bk.ru)

\title{
НЕПРАВИТЕЛЬСТВЕННЫЕ ОРГАНИЗАЦИИ ПО ЗАЩИТЕ ПРАВ БЕЖЕНЦЕВ ВО ФРАНЦИИ: РЕАЛИИ ПРОДОЛЖАЮЩЕГОСЯ КРИЗИСА
}

\begin{abstract}
Аннотация. Работа неправительственных организаций по защите прав беженцев во Франции имеет давнюю историю, наполненную большим опытом. После прохождения пика миграционного кризиса 2015 г. НПО расширили спектр мероприятий по поддержке мигрантов - от раздачи еды до психологической и юридической помощи женщинам-мигрантам, подвергшимся домашнему насилию. Однако главными задачами последнего времени для них стали огласка и нивелирование неудачных последствий цифровизации подачи и обработки документов, легализующих пребывание мигрантов в стране.

Ключевые слова: миграция, миграционный кризис, неправительственные организации, Франция, цифровизация, цифровизация документооборота
\end{abstract}

$\mathrm{M}$ играционный кризис 2015 г. стал глобальной проблемой Европы, оказавшейся неготовой к принятию и интеграции нахлынувшего потока беженцев. Начало предварительной фазы кризиса датируется 2010 г., когда в Европе начал фиксироваться рост прибывающих беженцев из зон конфликтов.

По данным Евростата, в 2014 г. (за год до острой фазы кризиса 2015 г.) страны ЕС получили 626065 заявлений о предоставлении убежища. Для сравнения, до этого наибольшим потоком считались беженцы из зоны югославских войн: в 1992 г. их численность составила $672000^{1}$. Основными странами происхождения заявителей в этот раз были Сирия (20\%), Афганистан (7\%), Косово (6\%), Эритрея (6\%) и Албания. К странам ЕС, принявшим наибольшее число беженцев в конце 2014 г., относятся Франция (252 264 заявления), Германия (216 973), Швеция (142 207) и Великобритания (117 000)².

Наиболее острая фаза кризиса относится к апрелю 2015 г., когда о кризисе заговорили уже на самом высоком уровне. Именно тогда более 1200 беженцев из Африки, переплывавших Средиземное море в направлении Европы, потерпели крушение близ о. Лампедуза (около 800 из них погибли) ${ }^{3}$. Этот год ознаменовался еще более значительным ростом числа беженцев. Однако, по данным Евростата 4 , в 2015-2017 гг. Франция, оставаясь в числе лидеров по числу беженцев, подавших заявление на предоставление убежища в Европе (276 340), уступила первое место Германии (1 404 550).

В аспекте числа беженцев, по данным статистики, Франция несколько более

1 The number of asylum applicants in the EU jumped to more than 625000 in 2014. Eurostat. 2015. URL: https://ec.europa.eu/eurostat/documents/2995521/6751779/3-20032015-BP-EN. pdf/35e04263-2db5-4e75-b3d3-6b086b23ef2b (accessed 11.01.2022).

2 World at war. UNHCR Global Trends 2014. https://www.unhcr.org/556725e69.html (11.01.2022).

3 The Mediterranean's deadly migrant routes. - BBC News. 22 April 2015. https://www.bbc. com/news/world-europe-32387224 (11.01.2022).

4 First instance decisions on applications by citizenship, age and sex - annual aggregated data (rounded). - Eurostat. 2021. https://ec.europa.eu/eurostat/databrowser/view/migr_asydcfsta/ default/table?lang=en (11.01.2022). 
плавно вошла в кризис, чем, например, Германия или другие страны, принявшие более 100000 беженцев в 2015-2017 гг. (см. табл. 1)

Таблица 1

Численность беженцев в 2014 г. и в 2015-2017 гг. в странах-лидерах, принявших в 2015-2017 гг. более 100000 беженцев

\begin{tabular}{|c|c|c|}
\hline Название страны & 2014 г. $^{{ }^{*}}$ & 2015-2017 $_{\text {гг. }}{ }^{* *}$ \\
\hline Германия & 216973 & 1404550 \\
\hline Франция & 252264 & 276340 \\
\hline Италия & 93715 & 239455 \\
\hline Швеция & 142207 & 205405 \\
\hline Австрия & 55598 & 108670 \\
\hline
\end{tabular}

* World at war. UNHCR Global Trends 2014. Доступ: https://www.unhcr.org/556725e69.html (проверено 11.01.2022).

First instance decisions on applications by citizenship, age and sex - annual aggregated data (rounded). Eurostat. 2021. Доступ: https://ec.europa.eu/eurostat/databrowser/view/migr_ asydcfsta/default/table?lang=en (проверено 11.01.2022).

Кроме того, Франция имеет более давнюю и насыщенную историю миграционных процессов. Важный задел опыта принятия и адаптации мигрантов Франция получила еще в XX в. Тогда Франция избегала принципа квот на гражданство, который практиковался в англоязычных странах и воплотился, например, в акте Джонсона-Рида 1924 г., препятствовавшем миграции из Азии в США. Франция принимала граждан из разных стран, например, в 1938 г. было принято около 440000 мигрантов из Испании, бежавших из зоны гражданской войны [Andréo 2008: 42]. Хорошо известен факт об истории парижского метро, которое строилось силами жителей французских колоний, в частности кабилами ${ }^{1}$.

Наиболее массовой и исторически обусловленной стала миграция выходцев из стран Магриба, в частности из Алжира, Марокко и Туниса (по степени убывания).

Поскольку Алжир занимает в этой тройке первое место ${ }^{2}$, опишем важные этапы истории эмиграции его жителей во Францию. В 1962 г. Эвианские соглашения, положившие конец войне в Алжире и приведшие к исчезновению его французских департаментов, утвердили, что «алжирские граждане, проживающие во Франции, и, в частности, рабочие, будут иметь те же права, что и французские граждане, за исключением прав политических», и они смогут свободно перемещаться между Францией и Алжиром. Французские власти считали, что эта мера облегчит возвращение алжирских рабочих домой после обретения их страной независимости. Однако это привело к обратному - миграционному движению алжирских рабочих во Францию. В 1964 г. Франция установила квоту на въезд алжирских рабочих. С другой стороны, постановление от 21 июля 1962 г. предусматривало, что алжирцы-мусульмане с гражданским статусом (statut civil) в соответствии с местным законодательством, проживаю-

1 L’immigration algérienne en France. Доступ: https://www.histoire-immigration.fr/dossiersthematiques/caracteristiques-migratoires-selon-les-pays-d-origine/l-immigration-algerienne (проверено 11.01.2022).

2 Так, например, по оценкам алжирских экспертов, к 2009 г. из Алжира во Францию мигрировало около 4 млн чел. [Новоженова 2009: 80]. 
щие во Франции и желающие получить французское гражданство, должны до 23 марта 1967 г. сделать заявление о признании своего статуса. В общей сложности в то время 59903 алжирца с гражданским статусом в соответствии с местным законодательством (не включая харки ${ }^{1}$, подлежавших отдельным процедурам признания) выбирают французское гражданство в соответствии с Эвианскими соглашениями. После 1967 г. начинается процедура, известная как реинтеграция (восстановление гражданства) по указу (réintégrations par décret) [Gallissot 1997: 188].

Статус алжирских граждан сегодня регулируется франко-алжирским соглашением, подписанным 27 декабря 1968 г. $^{2}$ Данный документ касается передвижения, занятости и проживания алжирских граждан и их семей. Граждане Алжира могут получить специальный вид на жительство: удостоверение на право проживания во Франции иностранца - гражданина страны, не входящей в Европейское экономическое сообщество (certificat de résidence). Это может быть продлеваемый годичный сертификат, выдаваемый студентам, стажерам и работникам по срочным контрактам, или десятилетний сертификат для других работников. Для этого они должны предоставить подтверждение законного проживания во Франции не менее трех лет, стабильной работы и доходов. Этот документ могут также получить их близкие родственники в рамках процедуры воссоединения семьи.

Немаловажную помощь алжирским мигрантам оказывала, например, такая организация как Cimade, основанная в 1909 г. Члены этой организации выступали против колониализма, активно помогали алжирскому населению во время войны (1954-1962 гг.), способствовали адаптации алжирских мигрантов во Франции после ее окончания и провозглашения независимости Алжира [La Cimade... 2019: 29]. Позднее, с 1994 г. алжирским мигрантам во Франции стала активно помогать ассоциация Gisti, основанная в 1972 г.

Таким образом, уже на алжирском примере видно, что неправительственные организации помощи мигрантам имеют давнюю историю работы. Сегодня таких организаций насчитывается более $30^{3}$. Диапазон их действий довольно широк, и наиболее острые проблемы мигрантов выделены порталом InfoMigrants (IM) в соответствующие категории (см. табл. 2).

Представленная категоризация скрывает остроту одного из наиболее важных вопросов, который стал актуальным в последние годы и без которого решение остальных вопросов становится нескончаемой проблемой, а именно оформление документов. Например, мигранту без документов сложнее оказать медицинскую помощь в случае серьезной болезни, поскольку это требует официального оформления и медицинской страховки; его сложнее юридически обезопасить, поэтому организации, работающие с женщинами-мигрантами, пострадавшими от домашнего насилия, оказывают им в основном психологическую помощь.

Парадоксально, но этот вопрос обострился не только в силу миграционного кризиса, вернее, кризис в данном случае усугубил ситуацию.

С развитием цифровых средств коммуникации процедура оформления документов не просто замедлилась, но во многих случаях остановилась на годы. Находясь на территории Франции без документов, мигранты фактически ока-

1 Харки - военнослужащие из местных формирований алжирских мусульман, принимавшие участие в 1954-1962 гг. в сражениях на стороне Франции против Фронта национального освобождения во время Алжирской войны.

${ }^{2}$ Accord franco-algérien consolidé. - Gisti. Доступ: http://www.gisti.org/doc/actions/2001/ algeriens/accord.html (проверено 11.01.2022).

3 По данным портала InfoMigrants (IM). Доступ: https://www.infomigrants.net/fr/post/3944/ france--tour-dhorizon-des-associations-daide-aux-migrants (проверено 7.11.2021). 
Таблица 2

Основные проблемы мигрантов, в решение которых включены неправительственные организации Франции, по версии портала InfoMigrants (IM)

\begin{tabular}{|c|c|}
\hline $\begin{array}{c}\text { Категориальная } \\
\text { проблема }\end{array}$ & Неправительственные организации, ее решающие \\
\hline $\begin{array}{l}\text { Здоровье, } \\
\text { питание, одежда, } \\
\text { административные } \\
\text { вопросы }\end{array}$ & 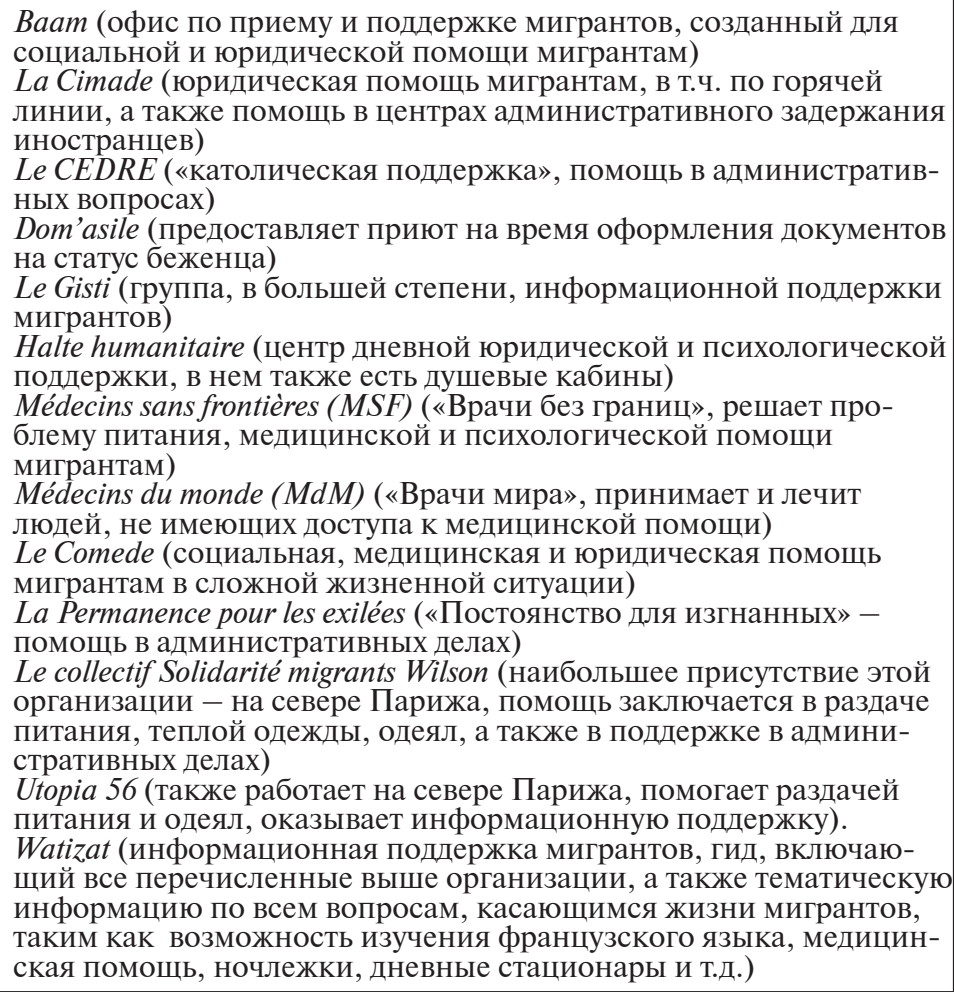 \\
\hline $\begin{array}{l}\text { Поддержка } \\
\text { мигрантов, } \\
\text { проживающих в } \\
\text { Кале }\end{array}$ & $\begin{array}{l}\text { L’Auberge des migrants (организует раздачу питания, одежды и одеял } \\
\text { мигрантам в этом регионе) } \\
\text { Utopia } 56 \text { (осуществляет постоянный объезд округа на автобусе с } \\
\text { целью помощи нуждающимся) } \\
\text { Salam (организует раздачу питания, одежды и одеял, также оказы- } \\
\text { вает поддержку при подаче документов на статус беженца) } \\
\text { Safe passage et Care4Calais (поддержка англоязычных мигрантов, } \\
\text { раздача спальных мешков и палаток, информационная под- } \\
\text { держка для желающих пересечь Ла-Манш и обосноваться в } \\
\text { Великобритании) }\end{array}$ \\
\hline $\begin{array}{l}\text { Поддержка } \\
\text { беженцев, } \\
\text { получивших } \\
\text { документы }\end{array}$ & $\begin{array}{l}\text { Singa (размещение беженцев, поддержка в профессиональных } \\
\text { проектах) } \\
\text { Action emploi réfugiés (помогает с написанием резюме и } \\
\text { трудоустройством) } \\
L^{\prime} A F P A \text { (помощь в освоении языка и обучении профессии) }\end{array}$ \\
\hline $\begin{array}{l}\text { Поддержка } \\
\text { мигранток, } \\
\text { пострадавших } \\
\text { от домащнего } \\
\text { насилия }\end{array}$ & $\begin{array}{l}\text { La Cimade (психологическая и юридическая помощь по горячей } \\
\text { линии по средам, утром и днем) } \\
\text { Kâli (горячая линия психологической помощи по четвергам, } \\
\text { вечером). } \\
\text { Rajfire (горячая линия по четвергам, вечером) } \\
\text { Femmes de la Terre («Женщины Земли», горячая линия в четверг } \\
\text { утром и в понедельник днем). }\end{array}$ \\
\hline
\end{tabular}


* Кале - город на севере Франции, паромный перевозчик через Ла-Манш. Известен тем, что во время пика миграционного кризиса 2015 г. в нем обосновался крупнейший лагерь беженцев, в котором были свои магазины, школы и даже бойцовский клуб [Agier et al. 2018].

Организации координируются между собой, чтобы, по возможности, оптимально охватить время работы горячей линии в течение рабочей недели.

зываются выброшенными из социальной жизни, они не могут устроиться на работу, завести счет в банке, арендовать жилье и т.д. При этом многие из них по закону имеют право на получение вида на жительство, в их число входят и те, кто получил международную защиту во Франции, и те, кто хочет продлить действие своих документов, выданных на год, два или десять лет. В ситуации полной безысходности, нарушения прав мигранты могут обратиться за помощью к юристу, но, как правило, их финансовое положение не позволяет это сделать. Наряду с этим в отсутствие легализующих документов мигранты не могут отстаивать свои права самостоятельно, что нередко отягощается еще и незнанием языка, а также юридической неграмотностью. В этой связи единственным помощником становятся неправительственные организации: в период с 2017 г. их деятельность актуальна, как никогда прежде ${ }^{1}$.

С 2017 г. (а в отдельных округах - раныше) правительство Франции начало процесс цифровизации соответствующего документооборота 2 . Иностранные соискатели для разрешения на проживание во Франции должны подавать свое досье (только!) через соответствующий сайт и ожидать его одобрения в личном кабинете. После одобрения соискателю следует в соответствующем разделе сайта «ловить» свободное место для записи на прием в префектуре, чтобы подать оригиналы документов и сдать отпечатки пальцев (биометрия). Весь этот цифровизированный процесс получил название «упрощенная процедура запроса (на подачу документов)» (demarches-simplifiees ${ }^{3}$ ). До оцифровки процесса соискатели приходили в префектуру и подавали документы на прием в порядке живой очереди.

Фактическая ситуация оказалась таковой, что соискатели ожидали одобрения досье месяцами, но после его получения не могли попасть на прием в префектуру, чтобы подать документы и сдать отпечатки пальцев. Надпись, которая выдавалась при попытке записаться на прием, всегда гласила, что свободных мест нет, и призывала пытаться записаться позже.

Уже в 2018 г. в прессе появились первые сообщения о невозможности записаться на прием в префектуры (различных округов Франции) для мигрантов. Сообщения были инициированы такими неправительственными организа-

1 Эти вопросы неоднократно обсуждались в пресce. Dossiers en souffrance à la préfecture des Hauts-de-Seine: du mieux mais insuffisant selon les soutiens des étrangers. Le Parisien. 2021. Доступ: https://www.leparisien.fr/hauts-de-seine-92/dossiers-en-souffrance-a-laprefecture-des-hauts-de-seine-du-mieux-mais-insuffisant-selon-les-soutiens-des-etrangers13-10-2021-JGPCJGB5OFDL5J554HBAQFJ6NY.php (проверено 11.01.2022). Кроме того, многочисленные личные кейсы можно найти в соответствующих тематических группах в социальных сетях. См., например, группу общих вопросов по получению вида на жительство во Франции Titre - Carte de Sejour (103 тыс. чел.) Доступ: https:// www.facebook.com/groups/294967924319480/ (проверено 11.01.2022). Характерно также наличие групп, посвященных проблемам с подачей документов в конкретные префектуры, например Rex Démarche Siplifiée de Nanterre (782 чел.). Доступ: https://www.facebook.com/ groups/505360160909767/ (проверено 11.01.2022).

2 Цифровизация в рамках программы улучшения качества работы административных служб. Доступ: https://www.gouvernement.fr/action/action-publique-2022-pour-une-transformation-du-service-public (проверено 11.01.2022).

3 Сайт упрощенной процедуры запроса (на подачу документов) имеет одноименный домен. Доступ: https://www.demarches-simplifiees.fr/ (проверено 11.01.2022). 
циями, как Médecins du monde и Cimade 1 . Как сообщили сотрудники Cimade, по их статистике ${ }^{2}$, например, с марта по май 2018 г. из получивших международную защиту во Франции в $O F P R A^{3}$ и пытавшихся обратиться в префектуру Страсбурга для получения соответствующих документов только $20 \%$ смогли попасть на прием, остальные $80 \%$ столкнулись с отсутствием свободных мест.

В 2019 г., со ссылкой на данные НПО, о проблеме написала национальная газета Франции Le Parisien ${ }^{4}$, сообщив, что 20 юридических контор ведут «борьбу», инициированную Secours Catholique, Cimade, Gisti и др. и направленную на то, чтобы иностранцы могли получить положенный им по закону прием в префектуре для подачи документов. В том же году в издании Capital вышла статья, посвященная проблеме мошеннического рынка покупки свободных мест на прием в префектурах. Со ссылкой на данные Cimade, разработавшей программу-робота, в тестовом режиме осуществлявшего непрерывные заходы на сайты различных префектур, Capital сообщила, что свободных мест нет в течение уже долгого времени (в зависимости от конкретной префектуры от нескольких месяцев до почти двух лет). В прессе все больше поднимается вопрос о невозможности оформить положенные мигрантам (и другим иностранцам, включая студентов, специалистов, приехавших по рабочим визам, и т.д.) документы ${ }^{5}$. При этом СМИ неизменно опираются на данные вышеупомянутых НПО.

В начале 2020 г. вопрос о невозможности записаться на прием в префектуру поднимается в Национальной ассамблее. Однако на соответствующий запрос депутата Стефани Атжер государственный секретарь министра внутренних дел Лорьен Нуньес отвечает, что префектуры работают на пределе возможностей и что, например, для департаментов «малой короны» 6 среднее число обслуживаемых заявителей колеблется от 1400 до 2500 в день. Л. Нуньес уверяет, что динамика сокращения времени обработки запросов положительная ${ }^{7}$

Возможно, такое заявление могло иметь прогностическую силу, и динамика продолжала бы быть положительной, однако в ситуации наступившей вскоре пандемии и направленных против нее карантинных мер работа многих служб, в т.ч. и по работе с иностранными гражданами, замедлилась ${ }^{8}$. В 2020 г. (несмо-

1 См., например, заметку о невозможности попасть в префектуру Страсбурга на сайте Rue89.Strasbourg. 2018. Доступ: https://www.rue89strasbourg.com/chaque-dimanchecauchemar-nocturne-etrangers-pour-leurs-papiers-137780 (проверено 11.01.2022).

2 Там же.

3 Французское ведомство по защите беженцев и лиц без гражданства (Office français de protection des réfugiés et apatrides).

4 Carte de séjour: des étrangers qui n'arrivent pas à prendre rendez-vous à la préfecture attaquent l'Etat. - Le Parisien. 2019. Доступ: https://www.leparisien.fr/hauts-de-seine-92/ des-etrangers-qui-n-arrivent-pas-a-renouveler-leur-carte-de-sejour-attaquent-1-etat-enjustice-07-10-2019-8168286.php (проверено 11.01.2022).

5 Для подтверждения достаточно сделать поисковый запрос в разделе новостей Google за этот период по ключевым словам: Prendre un rendez-vous en Préfecture (получить запись на прием в префектуре) или Prendre un rendez-vous (получить запись на прием), Biométrie (биометрия) и т.д.

6 Зона из трех департаментов, образуюших ближайшие предместья Парижа: О-де-Сен, Сен-Сен-Дени и Валь-де-Марн.

7 Question orale sans débat N903 de Mme Stéphanie Atger. Assemblée nationale. 01.2020. Доступ: https://questions.assemblee-nationale.fr/q15/15-903QOSD.htm (проверено 11.01.2022).

8 Dossiers en souffrance à la préfecture des Hauts-de-Seine: du mieux mais insuffisant selon les soutiens des étrangers. - Le Parisien. 2021. Доступ: https://www.leparisien.fr/hauts-de-seine-92/ dossiers-en-souffrance-a-la-prefecture-des-hauts-de-seine-du-mieux-mais-insuffisant-selonles-soutiens-des-etrangers-13-10-2021-JGPCJGB5OFDL5J554HBAQFJ6NY.php (проверено 11.01.2022). 
тря на вышедшую на первый план новостную повестку пандемии) и в 2021 г. в прессе продолжает подниматься вопрос о невозможности получения документов мигрантами. В этом контексте в качестве информаторов и апологетов изменения системы записи на прием в префектуру через ее сайт продолжают фигурировать неправительственные организации, такие как Cimade. И, наконец, к сентябрю 2021 г. администрация соглашается с обвинениями в неэффективности своей работы, и на сайтах ряда префектур появляется надпись, обращенная к заявителям на получение документов: «Нет смысла записываться на прием через Интернет, поскольку сотрудник префектуры свяжется с вами напрямую в кратчайшее время» 1 .

Сейчас невозможно прогнозировать, принесет ли такое изменение пользу, ускорится ли процесс оформления документов. Но, учитывая опыт борьбы неправительственных организаций с бюрократической системой, можно сказать, что в случае очередного «торможения» легализации мигрантов роль НПО будет все более заметной.

\section{Список литературы}

Новоженова И.С. 2009. Алжирская диаспора во Франции. - Актуальные проблемы Европы. № 4. С. 77-100.

Agier M. et al. 2018. La jungle de Calais : les migrants, la frontière et le camp. Paris: PUF. 224 p.

Andréo G. 2008. Les réfugiés espagnols dans le département de l'Isère, 19361939. Histoire. Доступ: https://dumas.ccsd.cnrs.fr/dumas-00295837/file/Les_refugies_espagnols_dans_le_departement_de_1_Isere_1936_1939.pdf (проверено 11.01.2022).

Gallissot R. 1997. Les Accords d'Évian: en conjoncture et en longue durée. Paris: Khartala. 272 p.

La Cimade. Une histoire. 2019. Paris: La Cimade. 92 p.

VERIGA Valerii L'vovich, Applicant at the Chair of World Political Processes, Moscow State Institute of International Relations, University of the Ministry for Foreign Affairs of Russia (76 Vernadskogo Ave, Moscow, Russia, 119454; vlveriga@ bk.ru)

\section{NON-GOVERNMENTAL ORGANIZATIONS FOR THE PROTECTION OF REFUGEES IN FRANCE: THE REALITIES OF THE ONGOING CRISIS}

\footnotetext{
Abstract. The work of non-governmental organizations for the protection of the rights of refugees in France has a long history filled with great experience. After passing the peak of the migration crisis in 2015, they expanded the range of problems they deal with in supporting migrants: from distributing food to psychological and legal assistance to women migrants who had experienced domestic violence. However, the main tasks of recent times for them have become publicity and leveling the unfortunate consequences of the digitalization of the filing and processing of documents that legalize the stay of migrants in the country.

Keywords: migration, migration crisis, non-governmental organizations, France, digitalization, digitalization of workflow

1 Biometrie - prise des empreintes digitales. Les services de l'État dans les Hauts-de-Seine. Доступ: https://www.hauts-de-seine.gouv.fr/Demarches-administratives/Etrangers-en-France/ SEJOUR/SEJOUR-prefecture-de-Nanterre/Autres-demarches-liees-au-sejour/BIOMETRIEPRISE-DES-EMPREINTES-DIGITALES (проверено 11.01.2022).
} 